\title{
Esophageal and pharyngeal strictures: report on 1,862 endoscopic dilatations using the Savary-Gilliard technique
}

\author{
Elsa Piotet $\cdot$ Anette Escher $\cdot$ Philippe Monnier
}

Received: 1 June 2007 / Accepted: 10 September 2007 / Published online: 26 September 2007

(C) Springer-Verlag 2007

\begin{abstract}
Treatment of symptomatic pharyngeal and esophageal strictures requires endoscopic dilatation. The Savary-Gilliard bougienage was developed by our department and has been used since 1980 for this purpose. We report our experience using this technique. The records of patients seen from January 1, 1963 to December 31, 2005, who had pharyngeal and esophageal strictures needing dilatation, were reviewed. The prevalence of different etiologies, and the incidence of complications using the SavaryGilliard dilators were assessed. Efficiency of dilatation was assessed over a 17 -year segment of this period, using number of dilatations and time intervals between dilatations until resolution of symptoms as outcome measures. Of the 2,652 pharyngeal and esophageal strictures reviewed, 90\% were of organic origin ( $45 \%$ benign and $55 \%$ malignant stenoses), and $10 \%$ were of functional etiology. The most common etiologies were peptic strictures before the era of proton pump inhibitors, and postoperative anastomotic strictures thereafter. A total of 1,862 dilatations using the Savary-Gilliard technique were analyzed. Complication and mortality rates were 0.18 and $0.09 \%$ for benign and 4.58 and $0.81 \%$ for malignant etiologies, respectively. The number of dilatations per stricture and the time interval between different sessions were dependent on the type of strictures, varying from 1 to 23 dilatations and 7 days to 16 years, respectively. Pharyngeal and esophageal dilatations using the Savary-Gilliard technique were safe when used together with fluoroscopy. Overall, the efficiency of
\end{abstract}

E. Piotet $(\bowtie) \cdot$ A. Escher $\cdot$ P. Monnier

Department of Otolaryngology,

Head and Neck Surgery,

University Hospital of Lausanne,

1011 Lausanne, Switzerland

e-mail: elsa.piotet@chuv.ch the dilatation procedure was good, but some types of strictures (e.g., caustic, post-surgical and/or post radiotherapy) were refractory to treatment and required repeated dilatations.

Keywords Esophageal stricture - Pharyngeal stricture . Esophageal dilatation · Savary-Gilliard bougies .

Esophageal perforation

\section{Introduction}

Patients with hypopharyngeal and esophageal strictures initially present with dysphagia to solids, which progresses to liquids over time. The degree of dysphagia is correlated with the size of the esophageal lumen: a diameter less than $12 \mathrm{~mm}$ always produces dysphagia with consumption of a normal diet. Other symptoms may include chest or abdominal pain, weight loss and possibly regurgitation and aspiration if the stricture is located in the upper esophagus.

Esophageal strictures can be divided grossly into two categories, according to their benign or malignant etiology. Among the benign strictures, functional and organic origins must be distinguished: functional strictures are the consequence of increased tonicity of the muscular wall while benign organic strictures mainly result from collagen deposits and fibrous tissue formation induced by mucosal injuries of diverse origins.

Endoscopy to obtain a biopsy specimen is mandatory for excluding neoplasm and assessing stricture characteristics. Length, precise location regarding upper and lower esophageal sphincters, spontaneous lumen diameter and mucosal appearance should be evaluated. Strictures are considered complex when they are greater than $2 \mathrm{~cm}$ in length or are angulated, irregular or do not allow the passage of a pediatric endoscope [8]. 
Endoscopic dilatation is the first-line treatment for benign esophageal strictures. In malignant strictures, no attempt should be made to pass the stricture with forceful dilatation in order to avoid the risk of perforation, unless the tumor is short and requires that EUS endoscope be inserted to perform the initial staging of the tumor, or in palliative treatment with or without esophageal prosthesis placement.

Dilatations using carved whalebone were first reported in the seventeenth century [33], and numerous dilators have since been developed. Mercury-filled Maloney dilators are flexible bougies without guide wires that are used for blind dilatation of simple strictures. Wire-guided dilators include the Eder-Puestow metal olives, which are now obsolete, the Savary-Gilliard polyvinyl-chloride bougies and the balloon dilators. The Savary-Gilliard technique was developed in the Department of Otolaryngology, Head and Neck Surgery, University Hospital of Lausanne in 1980, with the aim of decreasing the perforation rate, which then varied from 0.5 to $9 \%$, depending on the dilatation system and the reported series [10, 22]. Another widely used system is the through-the-scope balloon dilator, which exerts only radial forces during dilatation and can be advantageous in some instances.

The purpose of this retrospective study was to review the records of all patients in our department, diagnosed with pharyngeal and esophageal strictures from 1963 through 2005, and to assess the safety and efficacy of the dilatations performed with the Savary-Gilliard technique since its introduction in 1980 .

\section{Materials and methods}

Our database was reviewed to assess number and etiologies of the pharyngeal and esophageal strictures necessitating dilatation in our department between January 1, 1963 and December 31, 2005. Dilatations with the Savary-Gilliard dilators have been exclusively used in our clinic since 1980, rather than using the Maloney dilators or the EderPuestow olives, except for some cases of achalasia that were managed by balloon dilatation. The Savary-Gilliard set included a metallic guide-wire and polyvinyl chloride bougies, ranging from 5 to $18 \mathrm{~mm}$ in diameter. The procedure has been described in detail elsewhere [26], and was always performed under fluoroscopy.

Results of dilatation using this procedure were reported as the number of dilatations per stricture and the time interval between the different sessions over a 17-year period (January 1, 1989 to December 31, 2005). These two factors were directly related to the efficiency of dilatation. In our institution, patients without relief of symptoms or in whom a lumen of $15 \mathrm{~mm}$ in diameter could not be obtained after the first dilatation were included in a dilatation program. This consisted of repeated dilatations every third week until permanent improvement was obtained. Patients for whom the first procedure was satisfactory were followed up and dilated only if dysphagia recurred. In case of gastroesophageal reflux disease (GERD)-induced strictures, the dilatation was followed by a proton pump inhibitor (PPI) treatment. Patients with achalasia were excluded from the analysis of results because of intermittent balloon dilatations. Neither were included strictures treated by other techniques in combination with dilatation, as $\mathrm{CO}_{2}$ laser for example.

Complications of dilatations were reported from January 1, 1980 to December 31, 2005. Severe complications were defined as potentially life-threatening situations and were assessed by reviewing the surgeon's endoscopy report. If the surgeon's report described any complications, then the patient's complete medical records were reviewed to determine any long-term effects of the complications.

\section{Results}

The retrospective analysis of our database showed a total of 2,652 pharyngeal or esophageal strictures requiring dilatation from 1963 to the end of 2005. There were 2,374 (90\%) organic strictures, among which 1,071 (45\%) were of benign and 1,303 (55\%) of malignant origin. Squamous cell carcinoma of the esophagus was by far the most frequent malignant etiology $(38 \%)$, followed by esophageal or gastric adenocarcinoma (20\%), and pharyngeal squamous cell carcinoma $(5 \%)$.

Etiologies for benign organic strictures are reported in Table 1. Non-organic or functional origins represented $10 \%$ of the data, with a total of 278 strictures. These were further divided into cricopharyngeal hypertonia (50\%), achalasia (47\%), and pylorus hypertonia after transhiatal esophagectomy $(3 \%)$.

The total prevalence of esophageal strictures requiring dilatation among patients undergoing upper digestive endoscopy was $6,2.7 \%$ for benign organic, $3 \%$ for malignant and $0.3 \%$ for functional strictures, respectively.

A total of 1,862 dilatations using the Savary-Gilliard technique were performed, 1,120 (60\%) for benign strictures and 742 (40\%) for malignant strictures. Dilatation was followed by esophageal prosthesis placement in 457 cases of neoplasia. Ninety-two (4.9\%) procedures were performed for pharyngeal strictures, the etiologies of which are reported in Table 2 .

The number of sessions per patient extended from 1 to 23 during the review period and was highly dependent upon the etiology of the stenosis, as shown in Table 3 . Time 
Table 1 Features of benign organic strictures at CHUV from 1963 to 2006

\begin{tabular}{lrrl}
\hline Etiology & Male & Female & Total $(\%)$ \\
\hline Peptic & 290 & 166 & $456(42.58)$ \\
Iatrogenic & 275 & 90 & $365(34.08)$ \\
Post-RT \pm CT, post-PDT & 53 & 21 & $74(6.91)$ \\
Post-surgery & 159 & 59 & $218(20.35)$ \\
Post-surgery + RT & 53 & 5 & $58(5.42)$ \\
Post-sclerotherapy & 7 & 2 & $9(0.84)$ \\
Pill-induced & 3 & 3 & $6(0.56)$ \\
Caustic & 36 & 36 & $72(6.72)$ \\
Web & 26 & 46 & $72(6.72)$ \\
Schatzki's ring & 39 & 12 & $51(4.76)$ \\
Undetermined & 15 & 7 & $22(2.05)$ \\
Pseudodiverticulosis & 7 & 0 & $7(0.65)$ \\
Epidermolysis bullosa & 3 & 4 & $7(0.65)$ \\
Ringed esophagus & 4 & 1 & $5(0.47)$ \\
Pemphigoid mucosynechiant & 0 & 4 & $4(0.37)$ \\
Candidiasis & 3 & 0 & $3(0.28)$ \\
Lichen planus & 0 & 2 & $2(0.18)$ \\
Submucosal fibrosis & 2 & 0 & $2(0.18)$ \\
Scleroderma & 0 & 1 & $1(0.09)$ \\
Post traumatic & 1 & 0 & $1(0.09)$ \\
Myofibromatosis & 1 & 0 & $1(0.09)$ \\
Total & 362 & 1,071 \\
\hline RT Radion & & &
\end{tabular}

$R T$ Radiotherapy; $C T$ chemotherapy; $P D T$ phototherapy

Table 2 Etiologies of pharyngeal strictures dilated from 1989 to 2006

$R T$ Radiotherapy;

$C T$ Chemotherapy

\begin{tabular}{lr}
\hline Etiology & $n$ \\
\hline Iatrogenic & 42 \\
Post-RT \pm CT & 8 \\
Post-surgery & 7 \\
Post-surgery + RT & 27 \\
Caustic & 1 \\
Post traumatic & 1 \\
Epidermolysis bullosa & 1 \\
Malignant & 6 \\
Total & 51 \\
\hline
\end{tabular}

interval between dilatations varied from 7 days to 16 years, as reported in Table 4.

Severe complications included esophageal perforation in 34 patients $(1.83 \%)$, all but one presenting with malignant strictures, and massive bleeding was documented in two patients $(0.11 \%)$. The mortality rate was $0.38,0.09 \%$ in benign and $0.81 \%$ in malignant strictures, respectively, with death occurring in seven patients secondary to perforation. Our overall complication rate was $1.93,0.18 \%$ for benign and $4.58 \%$ for malignant strictures, respectively.
Table 3 Number of dilatations per stricture from 1989 to 2006

\begin{tabular}{llll}
\hline Etiology (number of strictures) & Median & Mean & Range \\
\hline Pill-induced (2) & 1 & 1 & 1 \\
Lichen planus (2) & 1 & 1 & 1 \\
Scleroderma (1) & 1 & 1 & 1 \\
Pseudodiverticulosis (3) & 1 & 1 & 1 \\
Myofibromatosis (1) & 1 & 1 & 1 \\
Web (10) & 1 & 1 & $1-2$ \\
Undetermined (15) & 1 & 1 & $1-2$ \\
Pylorus hypertonia (6) & 1 & 1 & $1-2$ \\
Epidermolysis bullosa (3) & 1 & 1.5 & $1-3$ \\
Peptic (54) & 1 & 2 & $1-9$ \\
Mycotic (3) & 1 & 3 & $1-7$ \\
Submucosal fibrosis (2) & 1.5 & 1.5 & $1-2$ \\
Ringed esophagus (5) & 2 & 1.5 & $1-2$ \\
Schatzki's ring (4) & 2 & 3 & $1-6$ \\
Post-surgery (78) & 2 & 2.5 & $1-20$ \\
Post-RT (48) & 2 & 3 & $1-17$ \\
Post-surgery + RT (58) & 2 & 3 & $1-23$ \\
Caustic (14) & 2.5 & 3.5 & $1-11$ \\
Post traumatic (1) & 3 & 3 & 3 \\
\hline$R T$ Radiotherapy & & &
\end{tabular}

$R T$ Radiotherapy

\section{Discussion}

Etiology of strictures

Benign strictures were primarily organic (79\%), with GERD-related strictures being the most frequent etiology (43\%). They accounted for $52 \%$ of the benign organic strictures before 1989 , but dropped to only $18 \%$ after this period (Figs. 1, 2). The introduction of PPIs, commercialized in 1989, accounts for the fall in the prevalence of these lesions. It is now well recognized that the use of PPIs decreases the need for repeated dilatations in patients presenting with peptic strictures $[3,23,34]$. This pathology is estimated to occur in 7-23\% of patients with untreated reflux esophagitis [29]. Endoscopically, peptic strictures are nearly always located at the squamo-columnar junction (either at the Z-line, or at the upper pole of a Barrett's esophagus). They are generally short and symmetrical, with frequent signs of proximal erosive esophagitis. The initial stage of this esophageal narrowing results from edema and muscular spasm and is reversible with adequate antacid treatment. Progression of the disease results in erosions and deep ulcerations, leading to scarring of the submucosa and muscularis propria with narrowing of the digestive tract [29].

Iatrogenic strictures are the second most common etiology found in our series between 1963 and 2006. They represent $34 \%$ of our benign organic strictures. Since 1989, 
Table 4 Time interval between dilatations of strictures from 1989 to 2006

$R T$ Radiotherapy

\begin{tabular}{llll}
\hline $\begin{array}{l}\text { Etiology } \\
\text { (total number of strictures) }\end{array}$ & Median & Mean & Range \\
\hline Schatzki's ring (11) & 4 years & 4 years & $2.5-6$ years \\
Ringed esophagus (8) & 5 months & 20 months & 2.5 months-4.5 years \\
Mycotic (9) & 4 months & 5.5 months & $2.5-11$ months \\
Peptic (102) & 2 months & 9.5 months & 12 days-3 years \\
Post-surgery (198) & 2 months & 4.5 months & 10 days-38 months \\
Post-RT (136) & 2 months & 4 months & 9 days-7 years \\
Caustic (50) & 1.5 months & 9 months & 14 days-16 years \\
Post-surgery + RT (176) & 1.5 months & 7 months & 7 days-4 years \\
\hline
\end{tabular}

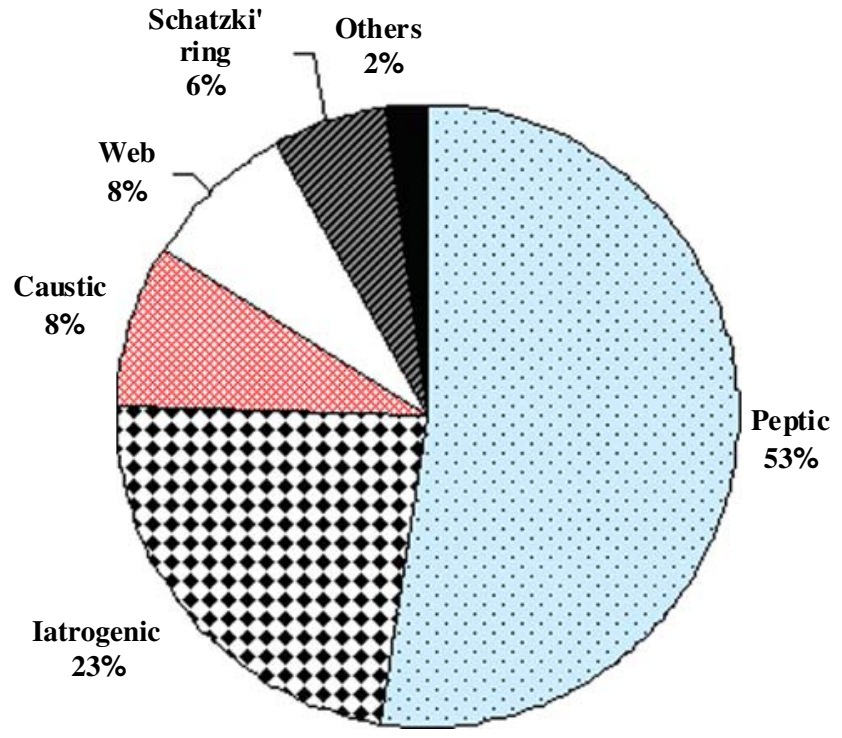

Fig. 1 Etiologies of benign organic strictures from January 1, 1963 to December 31, 1988

they have become the most common etiology, representing $61 \%$ of the study sample. Apart from commercialization of PPIs, there is a potential referential bias accounting for this large number. Patients presenting with a history of upper aerodigestive tract neoplasia are regularly followed up in our department, or referred to us by digestive surgeons if dysphagia recurs, whereas patients with GERD-related problems may be referred by their attending physician to the gastroenterology department rather than to Otolaryngology. A majority of iatrogenic strictures are of postoperative etiology, and this number increases with adjuvant therapy. In our series, most of the postoperative strictures resulted from esophagectomy, whereas in the group of combined radio-surgical treatment, total laryngectomy and/or pharyngo-laryngectomy predominated.

Benign strictures located at the esophago-gastric anastomosis in the upper thorax have been reported to be a major source of morbidity after transhiatal esophagectomy with a prevalence of $5-46 \%$, depending on the series. Risk factors reported for developing such strictures are postoperative

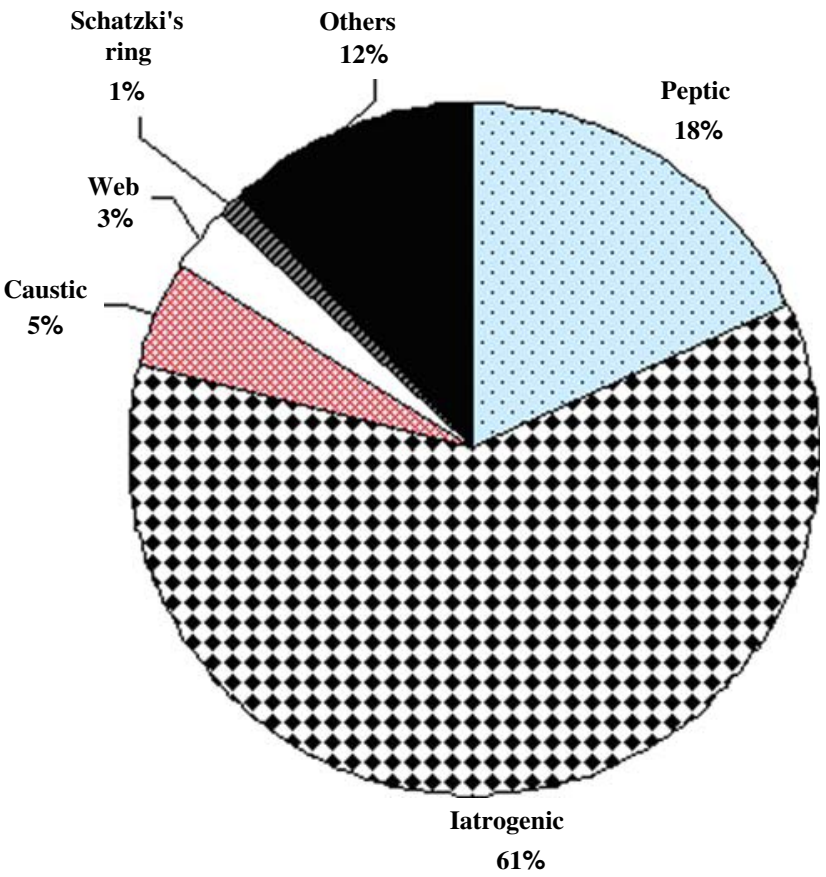

Fig. 2 Etiologies of benign organic strictures from January 1, 1989 to December 31, 2005

anastomotic leaks, stapled anastomosis (possibly because of insufficient mucosal apposition), cardiac disease, and poor vascularization of the gastric tube, the latter two resulting in anastomotic ischemia [13, 28].

Post-radiotherapy strictures of the hypopharynx and esophagus have been reported frequently and represented $12 \%$ of benign organic strictures in our series. The esophagus is known to be a fragile and radiosensitive organ, and late radiation injury is a common consequence of treatment of head and neck, lung, esophageal and breast tumors. Development of strictures is related to progressive obliterative endarteritis, ischemia and slowly developing fibrosis $[18,32]$. The severity of strictures varies from a fibrous ring of the esophageal inlet to deep fibrosis with possible subtotal obliteration of the lumen, which occurs generally in the setting of hypopharyngeal tumors. There are numerous 
factors predisposing a patient to develop strictures following radiation. The most important is the total absorbed dose; doses greater than $60 \mathrm{~Gy}$ predispose the structures to stricture formation [32]. Other factors include increased volume of irradiation in locally advanced tumors and circumferential irradiation [24]. Lee et al. reported a $21 \%$ prevalence of symptomatic strictures in a group of patients primarily treated with concurrent chemoradiation therapy for head and neck cancer. In this study, the risk factors included radiation therapy performed twice daily, primary tumors situated in the hypopharynx and female gender [19]. Although prevalence of strictures with concomitant chemotherapy has not been specifically investigated, the increased mucosal toxicity of these treatments is well known, and a higher degree of esophageal-wall fibrosis can be expected than after radiotherapy alone. Chronic xerostomy provoked by oropharyngeal irradiation impedes acid neutralization in the esophagus and may also predispose the patient to esophagitis [17] and development of stricture. Another evoked risk factor is prolonged enteral nutrition during radiotherapy, explained by the decreased activity of the hypopharyngeal and esophageal musculature predisposing the area to mucosal adhesions and fibrosis [9]. Percutaneous endoscopic gastrostomy has been suggested as a factor that increases the need for dilatation when compared to nasogastric tube, because of the lack of a stent-like effect [25]. Time of stricture onset after radiotherapy differs, according to the literature. Eisbruch et al. [6] assessed swallowing disorders after chemoradiation therapy for head and neck cancer in 26 patients and found that most strictures developed 1-3 months post-treatment and remained stable thereafter. Other authors have reported later onset of strictures, with median values varying from 6 to 26 months after radiotherapy [18, 32].

Pill-induced stricture is a rare condition $(0.6 \%$ of our series), but its incidence is likely to increase with aging of the population and greater use of medication. This condition results from pill-induced esophagitis provoked by an increase in time of contact with the mucosa when the drug is ingested in a supine position or without enough intake of water. Strictures are more likely to develop after $\mathrm{KCl}$, quinidine, ferrous sulfate/succinate and alprenolol ingestion [15]. Prevalence of strictures was $6 \%$ among the 51 cases of pill-induced esophagitis diagnosed in our department [27].

Esophageal strictures are one of the main complications of caustic ingestion, the second being late cancerization. Strictures develop during the scarring period 3-8 weeks after ingestion, secondary to sclerosis and infection. Circular lesions or those involving the muscular layers (second and third degree burns) are more prone to evolve into strictures. They are more often provoked by alkali than by acid ingestion, since the latter is mainly damaging the pharynx and the stomach. These strictures represent $7 \%$ of our data and have some specific endoscopic features. Among the 73 caustic strictures reviewed by Brossard et al. [4], 60\% were located in the upper esophagus, $48 \%$ were multiple and $49 \%$ measured more than $3 \mathrm{~cm}$ in length.

Webs are relatively frequent upper esophageal strictures of unknown origin. They represent $7 \%$ of our benign organic strictures with a female predominance $(64 \%)$. According to our data, upper esophageal webs are isolated entities. However, they have been associated with iron deficiency in "Plummer-Vinson syndrome". This entity is now largely questioned, and its prevalence has been falling during the last decade due to improvements in nutritional status [2].

Schatzki's ring is a thin annulus present in the lower esophagus, most of the time at the upper pole of a hiatal hernia, representing $5 \%$ of our benign organic strictures. Histologically, it is characterized by a proliferation of connective tissue in the submucosa, most probably resulting from GERD-carditis. It has a tendency to decrease in diameter over time, and strictures less than $13 \mathrm{~mm}$ always provoke dysphagia [31].

Intramural pseudodiverticulosis is a rare cause of benign stricture predominantly affecting men and representing less than $1 \%$ of our data. Its prevalence has been reported to be $0.15 \%$ [21]. The features of this disease are dilatation of the mucous gland excretory ducts from the submucosa, resulting in multiple intramural diverticula. Periglandular fibrosis and peridiverticulitis with associated stricture are present in more than $90 \%$ of cases [12]. The pathogenesis is still unknown, but increased incidences of candidiasis, GERD, diabetes mellitus, chronic alcohol abuse and poor general health, have been reported [7, 12].

Ringed esophagus, also called trachea-like or corrugated esophagus is a condition of unknown origin affecting young men predominantly. It represents only $0.47 \%$ of our benign strictures and is characterized by segmental strictures of various lengths containing multiple submucosal rings that are hard in consistency, generally without associated esophagitis. Several studies have reported results from patients with long-standing intermittent dysphagia, the so-called "slow-eaters", or with a history of food impaction [37]. When dilated, these strictures tend to show longitudinal tears with little if any bleeding. This is a common feature of this condition, which could be due to a submucosal fibrosis, possibly induced by recurrent episodes of fungal infection.

Other rare causes of benign strictures in our data are reported in Table 1, and include several dermatologic diseases, mycosis and sclerodermia.

\section{Results of dilatations}

Our review revealed a wide range of variability in efficiency of dilatation as a function of the etiology of 
lesions. This was correlated to the morphologic features of each type of stricture. As expected, before the era of stent placement, malignant strictures needed repeated dilatations as tumors were regrowing, with a median interval of 2 months between interventions. The results of dilatations of neoplastic strictures are highly dependent on the growth rate of the tumor. Therefore, they were not compared to the outcome of dilatations of benign strictures.

For benign strictures, efficiency of dilatations depended upon the extent of involvement of the esophageal wall by fibrosis and inflammatory processes.

The group that responded poorest to dilatation included caustic, postoperative and post-radiation therapy strictures. During the 17-year period reviewed, the median number of dilatations per patient was 2-2.5 (see Table 2), with a maximum of 23 dilatations for one patient. Median interval between dilatations was between 1.5 and 2 months (see Table 3), reflecting the high proportion of patients who entered a dilatation program. According to our data, caustic and post-surgery and/or post-radiotherapy strictures were the most refractory to dilatation. This is in agreement with the data reported in the literature [8].

Caustic strictures are known for their extension in length and involvement of the entire thickness of the esophageal wall. This results in tubulization of the scarred esophagus with increased difficulty for efficient dilatation. The outcome of caustic-stricture dilatations in our department was reported by Leuba et al. [20]. They found that when the length of the stenosis is greater than $3 \mathrm{~cm}$ in the cranio-caudal axis, management with dilatations is often insufficient, and indication for esophagectomy with coloplasty to restore normal oral intake must be discussed if there is no improvement of symptoms after a few dilatation sessions. Surgical management must be taken into consideration especially in young patients because of late cancerization.

Postoperative and postradiotherapy strictures also often need repeat dilatations, and a combination of these two treatment modalities further increases the number of dilatations per stricture. Some patients may be dilated once and then be asymptomatic, but most of them need multiple dilatations and inclusion in dilatation programs. Thereafter, the frequency of repeat dilatations is dictated by recurrence of dysphagia, with symptom-free intervals varying widely from days to several years. The circular involvement and the transmural fibrosis due either to peri-anastomotic inflammation, radiation or both, account for the tendency of the lesion to recur.

Another distinct group includes webs, which usually respond very well to dilatations. The median number of dilatations per stricture was one in this group, with a maximum of two dilatations per patient. A single dilatation is sufficient for complete resolution of symptoms in most patients.
Strictures related to dermatologic diseases, fungal infections, connectivitis or pill-induced strictures also tend to respond well to dilatation, but their small number in this sample does not allow us to draw any conclusions from the data.

A third group of strictures, in which response to dilatation is rather good but with frequent relapses, includes peptic strictures, Schatzki's rings and ringed esophagus.

The few cases of Schatzki's rings and ringed esophagus in our series generally required more than a single dilatation (median 2) and had long-term recurrence. Nevertheless, the symptom-free period after a single dilatation was 4 years for Schatzki's ring and 5 months for ringed esophagus, which was much greater than for the refractory strictures described previously. Moreover, patients do not have to enter dilatation programs following this procedure. This supports the efficacy of a single dilatation for treatment of these lesions, which, however, tend to form again with time [14].

The majority of peptic strictures respond well to treatment and can be dealt with by a single dilatation and PPI oral intake. For patients necessitating several dilatations, the median interval between procedures is 2 months (range 12 days to 3 years). This reflects the need for some patients to enter a dilatation program, whereas others have a long symptom-free interval and a late recurrence. This emphasizes the problem of patients' compliance to long-term drug intake, with the possible recurrence of stricture after years because of PPI cessation.

Said et al. [30] performed a retrospective analysis of risk factors for stricture recurrence within 1 year after symptom-releasing dilatation in 87 patients presenting with benign strictures. They showed an overall $40 \%$ recurrence rate within 1 year, with several significant risk factors. Strictures with an initial diameter of $13 \mathrm{~mm}$ or below and nonpeptic strictures were more prone to recur. Unfortunately, different etiologies of nonpeptic strictures were not sorted out in the analysis, because, as mentioned previously, recurrences differ widely depending upon the etiology. Among peptic strictures, a greater recurrence was seen in patients presenting with heartburn after dilatation, or a hiatal hernia greater than $5 \mathrm{~cm}$ in length.

As far as localization of strictures is concerned, the outcome after dilatation was overall better for esophageal than for pharyngeal strictures, but the latter were mostly iatrogenic in origin, belonging to the less favorable group. When compared with esophageal strictures of iatrogenic origin, the outcome of pharyngeal strictures was similar, confirming that the morphologic features of the lesion are more prominent than its localization. However, there might be a potential selection bias because some severe pharyngeal strictures were managed in combination with $\mathrm{CO}_{2}$ laser radial incisions. They were therefore excluded from the study. 


\section{Complications}

Slight bleeding and mucosal erosions are frequently seen after esophageal dilatations, and these conditions resolve spontaneously without specific management. Nevertheless, two severe and potentially life-threatening complications may occur, namely esophageal perforation and hematemesis. Post-dilatation esophagoscopy should always be performed to rule out such lesions.

Two cases of massive bleeding were reported over the 26-year period of this series, one for a malignant and another for a benign stricture in a patient treated with anticoagulants. Overall, the rate of severe hemorrhage was $0.11 \%$.

Esophageal perforation represents the primary severe complication of dilatation, with rapid progression to sepsis, mediastinitis and death. Rapid diagnosis and aggressive treatment are required. In our 26-year review, transmural perforation occurred once in the group of benign strictures because of faulty manipulation of the guide-wire, and 33 times in cases of malignant strictures. Overall, the perforation rate was $1.83,0.09 \%$ for benign and $4.45 \%$ for malignant strictures, respectively. The perforation rates in case of malignant strictures included both perforations during the dilatation procedure itself and during esophageal prosthesis insertion.

All cases of death secondary to dilatation occurred in the group of esophageal perforations with a fatal evolution in seven patients. The overall mortality rate was thus 0.38 , $0.09 \%$ for benign and $0.81 \%$ for malignant strictures, respectively.

Our results show that the Savary-Gilliard technique for esophageal dilatation of benign strictures is safe, with only $0.18 \%$ of severe complications. With a perforation rate of $0.09 \%$, we are at the lower limit of the $0.1-0.4 \%$ rate currently reported in the literature for esophageal dilatation in general $[1,8,11]$. The advantages of the Savary-Gilliard technique include the progressive flexibility of its guidewire and the tapered bougies exerting constant pressure on the esophageal wall, which provides the surgeon with feedback concerning resistance during the procedure. Moreover, all of the dilatations in our department were performed under fluoroscopy. This may also account for the reduced rate of complications. In the literature, dilatations with the Eder-Puestow olives are associated with higher perforation rates, ranging from 0.4 to $0.9 \%[16,36]$. The large gradient of pressure provoked by the form of these dilators and their extremely flexible guide-wire tip account for the higher perforation risk. This system is now obsolete. In the current literature, the perforation rate with the Maloney dilators is also reported to be higher than that with the Savary-Gilliard bougies. A study comparing perforation rates with Maloney, balloon and Savary dilators showed no perforation for the latter two procedures (156 and 90, respectively), and a $3.9 \%$ perforation rate for the Maloney dilators in 102 procedures [11]. Another prospective study of 300 patients dilated either with the Maloney, Savary-Gilliard, Eder-Puestow or balloon dilators, resulted in a single perforation, which occurred with a Maloney dilator used in the absence of fluoroscopy for dilatation of a Schatzki's ring [35]. Blind dilatation, as in the Maloney technique, increases the risk of misdirection of the dilator resulting in tracheal intubation, tearing or even perforation of the esophageal wall.

Finally, a randomized study by Cox et al. [5] showed better improvement on stricture diameter using the SavaryGilliard or the Eder-Puestow bougies than with balloon dilators. Safety of both methods was similar. Balloon dilators are also more expensive and cannot be used more than once. By contrast, Savary-Gilliard bougies may be reused indefinitely. At our institution, we are still using one of the same set of bougies that was used in 1980 when the technique was first developed. No problems with inter-individual contamination or infection have occurred.

In the case of malignant strictures, the perforation rate increased to $4.45 \%$ in our cohort of patients because of tearing of the tumor. However, this condition was often successfully managed by immediate trans-tumoral intubation. In these cases, the prognosis was better than for perforation of benign strictures. The mortality rate in cases of perforation of benign strictures was high (1/1 patient), whereas mortality for perforation of malignant strictures was $18 \%$ (6/33 patients). Tumoral infiltration surrounding the esophagus and forming a barrier to the mediastinum may account for the lower rate of bacterial dissemination and subsequent sepsis after perforation of large tumors.

\section{Conclusion}

Esophageal strictures treated in our department were primarily of iatrogenic origin $(61 \%)$ since the decrease in prevalence of peptic strictures secondary to the introduction of PPIs in 1989. Dilatation of benign strictures with the Savary-Gilliard technique was safe, even for complex strictures, with only two cases of severe complication out of a total of 1,120 procedures. We advise the systematic use of fluoroscopy during dilatation as it probably contributes to this low complication rate. Even if perforation is more likely to occur in cases of malignant strictures, this complication is usually well managed by esophageal prosthesis insertion.

Long-term efficiency of dilatation varies and is highly dependent on the etiology of the stricture. Even in cases of complex strictures, the median of 2-2.5 dilatations per patient over the 17-year period reviewed, showed that the overall efficacy is good and provide a satisfactory quality of life for most patients. 


\section{References}

1. American Society for Gastrointestinal Endoscopy (1998) Esophageal dilation. Gastrointest Endosc 48:702-704

2. Atmatzidis K, Papaziogas B, Pavlidis T, Mirelis CH, Papaziogas T (2003) Plummer-vinson syndrome. Dis Esophagus 16:154-157

3. Barbezat GO, Schlup M, Lubcke R (1999) Omeprazole therapy decreases the need for dilatation of peptic oesophageal strictures. Aliment Pharmacol Ther 13:1041-1045

4. Brossard E, Ollyo JB, Savary M, Monnier P (1993) Le rôle de la dilatation dans la prise en charge thérapeutique des sténoses caustiques de l'oesophage. Med Chir Dig 22:179-180

5. Cox JGC, Winter RK, Maslin SC, Dakkak M, Jones R, Buckton GK, Hoare RC, Dyet JF, Bennett JR (1994) Balloon or bougie for dilatation of benign esophageal stricture? Dig Dis Sci 39:776-781

6. Eisbruch A, Lyden T, Bradford CR, Dawson LA, Haxer MJ, Miller AE, Teknos TN, Chepeha DB, Hogikyan ND, Terrell JE, Wolf GT (2002) Objective assessment of swallowing dysfunction and aspiration after radiation concurrent with chemotherapy for head and neck cancer. Int J Radiat Oncol Biol Phys 53:23-28

7. Elabsi M, Echarrab M, Oudanane M, El Ounani M, Chkoff R, Zizi A (2002) Intramural pseudodiverticulosis of the oesophagus: a case report and review of literature. Ann Chir 127:637-640

8. Ferguson DD (2005) Evaluation and management of benign esophageal strictures. Dis Esophagus 18:359-364

9. Gillespie MB, Brodsky MB, Day TA, Lee FS, Martin-Harris B (2004) Swallowing-related quality of life after head and neck cancer treatment. Laryngoscope 114:1362-1367

10. Gotberg S, Afzelius LE, Hambraeus G, Hedenbro J, Lunderquist A, Owman T, Svensson G (1982) Balloon catheter dilatation of strictures in the upper digestive tract. Radiologe 22:479-483

11. Hernandez LJ, Jacobson JW, Harris MS (2000) Comparison among the perforation rates of Maloney, balloon and Savary dilation of esophageal strictures. Gastrointest Endosc 51:460-462

12. Herter B, Dittler HJ, Wuttge-Hannig A, Siewert JR (1997) Intramural pseudodiverticulosis of the esophagus: a case series. Endoscopy 29:109-113

13. Honkoop P, Siersema PD, Tilanus HW, Stassen LPS, Hop WCJ, van Blankenstein M (1996) Benign anastomotic strictures after transhiatal esophagectomy and cervical esophagogastrostomy: risk factors and management. J Thorac Cardiovasc Surg 111:1141-1148

14. Ibrahim A, Cole R, Qureshi WA, Helaly AZ, Jamecci A, Graham DY, Ayub K (2004) Schatzki's ring: to cut or break, an unresolved problem. Dig Dis Sci 49:379-383

15. Kikendall JM (1999) Pill esophagitis. J Clin Gastroenterol 28:298-305

16. Knutsen H, Fausa O (1990) Dilatation of esophageal stenoses. Tidsskr Nor Laegeforen 110:1711-1713

17. Korsten MA, Rosman AS, Fishbein S, Shlein RD, Goldberg HE, Biener A (1991) Chronic xerostomia increases esophageal acid exposure and is associated with esophageal injury. Am J Med 90:701-706

18. Laurell G, Kraepelien T, Mavroidis P, Lind BK, Fernberg JO, Beckman M, Lind MG (2003) Stricture of the proximal oesophagus in head and neck carcinoma after radiotherapy. Cancer 97:1693-1700

19. Lee WT, Akst LM, Adelstein DJ, Saxton JP, Wood BG, Strome M, Butler RS, Esclamado RM (2006) Risk factors for hypopharyn- geal/upper esophageal stricture formation after concurrent chemoradiation. Head Neck 28:808-812

20. Leuba D, Ollyo JB (1991) Corrosion de la voie digestive supérieure: bilan, traitement et résultats. Acta Endoscopica 21:665-668

21. Levine MS, Moolten DN, Herlinger H, Laufer I (1986) Esophageal intramural pseudodiverticulosis: a reevaluation. Am J Roentgenol 147:1165-1170

22. Luna LL (1983) Endoscopic treatment of esophageal strictures. Endoscopy 15:203-206

23. Marks RD, Richter JE, Rizzo J, Koehler RE, Spenney JG, Mills TP, Champion G (1994) Omeprazole versus H2-receptor antagonists in treating patients with peptic stricture and oesophagitis. Gastroenterology 106:907-915

24. Mavroidis P, Laurell G, Kraepelien T, Fernberg JO, Lind BK, Brahme A (2003) Determination and clinical verification of doseresponse parameters for esophageal stricture from head and neck radiotherapy. Acta Oncol 42:865-881

25. Mekhail TM, Adelstein DJ, Rybicki LA, Larto MA, Saxton JP, Lavertu $P$ (2001) Enteral nutrition during the treatment of head and neck carcinoma: is a percutaneous endoscopic gastrostomy tube preferable to a nasogastric tube? Cancer 91:1785-1790

26. Monnier P, Hsieh V, Savary M (1985) Endoscopic treatment of oesophageal stenosis using Savary-Gilliard bougies: technical innovations. Acta Endoscopica 15:119-129

27. Ollyo JB, Fontolliet CH, Wellinger J, Brossard E, Monnier P (1991) Les oesophagites "primitives" d'origine médicamenteuse: A propos de 978 observations (1970-1990). Acta Endoscopica 21:671-676

28. Pierie JPEN, de Graaf PW, Poen H, van der Tweel I, Obertop H (1993) Incidence and management of benign anastomotic stricture after cervical oesophagogastrostomy. Br J Surg 80:471-474

29. Richter JE (1999) Peptic strictures of the oesophagus. Gastroenterol Clin North Am 28:875-891

30. Said A, Brust DJ, Gaumnitz EA, Reichelderfer M (2003) Predictors of early recurrence of benign esophageal strictures. Am J Gastroenterol 98:1252-1256

31. Schatzki R (1963) The lower esophageal ring: long term follow-up of symptomatic and asymptomatic rings. Am J Roentgenol Radium Ther Nucl Med 90:805-810

32. Silvain C, Barrioz T, Besson I, Babin P, Fontanel JP, Daban A, Matuchansky C, Beauchant M (1993) Treatment and long-term outcome of chronic radiation esophagitis after radiation therapy for head and neck tumors. Dig Dis Sci 38:927-931

33. Spiess AE, Kahrilas PJ (1998) Treating achalasia: from whalebone to laparoscope. JAMA 280:638-642

34. Swarbrick ET, Gough AL, Foster CS, Christian J, Garrett AD, Langworthy CH (1996) Prevention of recurrence of oesophageal stricture, a comparison of lansoprazole and high-dose ranitidine. Eur J Gastroenterol Hepatol 8:431-438

35. Tucker LE (1992) Esophageal stricture: results of dilation of 300 patients. Mo Med 89:668-670

36. Yamamoto H, Hugues RW Jr, Schroeder KW, Viggiano TR, DiMagno EP (1992) Treatment of benign esophageal stricture by Eder-Puestow or balloon dilators: a comparison between randomized and prospective nonrandomized trials. Mayo Clin Proc 67:228-236

37. Younes Z, Johnson DA (1999) Congenital esophageal stenosis: clinical and endoscopic features in adults. Dig Dis 17:172-177 